\title{
COMMUNICATION STRATEGIES USED BY EFL LEARNERS IN TASK-BASED ENGLISH DEBATE
}

\author{
Novia Rina Saidah ${ }^{1}$ \\ Universitas Negeri Surabaya \\ Ahmad Munir ${ }^{2}$ \\ Universitas Negeri Surabaya \\ Syafi'ul Anam ${ }^{3}$ \\ Universitas Negeri Surabaya \\ $\underline{\text { noviarinasaidah@gmail.com }}$
}

Submit, 17-05-2020 Accepted, 21-06-2020 Publish, 21-06-2020

\begin{abstract}
This research aims to describe the use of communication strategies in an EFL classroom during the completion of task-based debate activity. This research was conducted in an English course located in Sidoarjo. The subject of this study are 10 EFL intermediate level students. In line with that reason, this research is a qualitative study since it focuses on the depth of the comprehension of the communication strategies data rather than computing it. For obtaining the data, the researcher do observation and records learners' verbal and non-verbal behaviour based on Dornyei (1995) taxonomy of communication strategies during the debate activity. The result showed that all taxonomies by Dornyei are used by the subjects i.e avoidance strategies, achievement strategies, and stalling strategies in the debate. There are various reason for leaners to choose those strategies to overcome their communication breakdowns during the short-time debate between speakers such as because it's time-efficient, less confusing, and sound trustworthy to lengthen their time to think, keep the communication channel at hand, and keep up the discourse at the moment when learners face the difficulties. As the conclusion, English debate activity is considered as one of the task that promotes students-centered learning in a TBLT class, provides opportunities for students to speak Engish, and challenge students to use their language sources to strengthen their arguments. In the debate, learners mostly applied stalling strategies such as fillers since is considered very easy and quick for learners to use when they encounter problems such as nervous, lack of vocab, and lack of grammar structure in the English debate activities.
\end{abstract}

Keywords: Communication strategies, task-based learning, English debate. 


\section{INTRODUCTION}

The development of English as a foreign language demands people to be able to communicate globally using English as the medium of their interaction. People need to exchange their intention, belief, and feeling in the form of verbal and non verbal utterances (Brown, 2000). Thus, as a social process which need signs, symbols, and languages as the resources to deliver meaning and generate understanding between people. Moreover, the priority to master English consequently makes people judge their succes in learning a language by how fluent and proficient their communication in English (Richards, 2008). However, as foreign language learners, they often encounter breakdowns that will cause problems in their process of communication. The problem mainly occurs when there is miscommunication or misunderstanding between speakers where the speakers' intended message differs from the message received by the interlocutors.

In Indonesian context in which English serves function as a foreign language, learners' often experience communication breakdowns since they have limited interlanguage sources compared to their first language (Putri, 2013; Cook, 1994). The different rules between their first language and English is also factors affecting their communication problem. Lack of vocabularies to express their utterances, poor grammar knowledge, poor pronunciation, and the limited opportunities to practice English outside the classroom also take part in creating problem in EFL learners' communication in English. Cunningham (1999) adds that for communicating, learners need to understand not only the linguistic components of the language but also the sociolinguistic aspects such as situation, time, and place. Moreover, psychological aspects such as low self-confident and low motivation cause learners' fear of making mistakes, get anxious or even hesitate in speaking English (Xiao, 2009).

However, in order to overcome those problems, learners' should try to find way out by using some communication strategies to remain in the flow of communnication and attain the goal of successful communication. The communication strategies serve function as negotiator device to deal with problems during the communication (Dornyei, 1995). Commuincation strategy provides alternative expression to convey meaning in surprising or unpredictable problems during communication and it helps learners' achieving the communicative competence which is the ultimate goal of foreign language learning. Concerning with those reasons, Task-based language teaching (TBLT) considered as appropriate method to enhance communication. It provides natural environment, great exposure, and chance for learners to use the target language (Willis \& Willis, 2007). It develops learners' creativity, cognitif process and problem solving which more to students-centered that allow them to be assigned 
to various kind of tasks and performances using the language communicatively (Widia \& Astawa, 2014). Hasan (2014) states that task-based approach gives comprehensible input and can encourage communicative interactions between learners by using the target language.

There are several studies have discussed task-based classroom activities in connection with communication strategies. Ghout-Khenoune (2012) in her study in Algerian university found that most of the communication strategies in Tarone's taxonomy are used by students in the free-talk activity. However, in the second task which is picture description, students utter less sentence and it causes low use of communication strategies. Meanwhile, Rosas (2018) in her study about jigsaw and free conversation for Spanish L2 learners found out that there is correlation between the task linguistic demands and students' use of communication strategies.

However, there is a few study which examines communication strategies in challenging and complex classroom task performance such as debate. Hence, according to that reason, this present study will focus to examine in detail the communication strategies used by EFL learners to solve their communication problems and to stay in the channel of the interaction during their performance in a classroom English debate. Debate considered as one of the activity that can promote task-based language teaching in facilitating learners' with authentic situation and elicit the use of communication strategies. Debate serves function as a performance talk in which convey information to the audience (Richards, 2008). It also gives learners the opportunity to use wide range of language such as comparing, justifying, persuding, and conclusion drawing.

\section{LITERATURE REVIEW}

\section{Communication Strategies}

The prime term of communication strategies was firstly suggested by Selinker in 1972. She proposed the term "strategies for second language learner" which later was elaborated in detail by Savignon in the same year with the new term "coping strategy" that refer to foreign or second language learners' way to deal with trouble during their communication caused by inadequate language resources. The result of those pilot studies then completed by (Tarone, 1980) on the first empirical study carried out related to communication strategies. She defined communication strategies as conscious sketch used to overcome the communication crisis when the language source is unsufficient to utter someone's intention. Moreover she classify communication strategies into three main categories and nine subcategories in it. Her taxonomies is still regarded as the most important because most of the following research rely on it. Later, those publications attracted the interest of many researches focusing on the 
communication strategies and its classifications including (Faerch \& Kasper, 1983), Bialystok (1990), Dornyei (1995), and López \& de Quintana (2011). They confronted the previous taxonomies and suggest the new ones. Most of the taxonomies are almost similar one another but may have different meaning on its applications. Those classifications differ mostly in the terminology the authors have used for the specific strategies occurs in communication (Popescu \& CohenVida, 2014).

However, in this study, the taxonomy proposed by Dornyei (1995) will be used to investigate the communication strategies used during debate activity since this taxonomy considered as the summaries of all taxonomies exist in the related research hence it is more inclusive than the other taxonomies. It includes both theoretical perspective; psycholinguistic and interactionist for the elicitation and identification of the communcation strategies (Rosas, 2018). Its also covers the new strategies which are not included in the other taxonomies such as use of similar sounding word, stalling or time gaining strategies, and foreignizing.

\section{Dornyei's (1995) Taxonomy.}

There are three main categoris with some sub categories on this taxonomy. Following are the brief description of each categories:

1. Avoidance strategies: Learners' decided to avoid the words that he presents as difficult or may cause problems during their performance and interaction. This covers two sub categories:

a. Topic avoidance: Learners avoid choosing the diffucult word/topic for their speaking.

b. Message abandonment: Learners leave the topic and simply give up then jump into the other topic. It can be marked by a sudden stop during the speaking.

2. Compensatory / Achievement strategies: Learners substitue the problems with other device. This covers ten sub categories:

a. Circumlocution: Learners elaborate the intended unknown word into description or illustration.

b. Approximation: Learners change the unknown word and choose the clostest meanaing word to their intended one.

c. All-purposed item: Learner repeating unimportant words.

d. Word coinage: Learners employ non-existing word in the target language.

e. Literal translation: Learners translate the word directly to the target language.

f. Foreignizing: Learners pronounce the L1 or L2 word like the target language.

g. Code switching: Learners shift to their L1 during communication. 
h. Repetition: Learners repeat their last words or phrases frequently.

i. Non-linguistic means: Learners use non-verbal device.

j. Appeal for help: Learners ask teacher or friends.

3. Stalling strategies: Learners use fillers and hesitation device for delaying time for thinking.

\section{Task-Based Language Teaching (TBLT)}

The core of task-based learning is communicative language teaching that enables learners actively using the target language in authentic language context where they can also enhance their language skill (Hashemi et al., 2012). This approach make use of "task" as the instrument to generate students-centered learning in natural and real-world language context rather than drilling and memorizing certain language form (Willis \& Willis, 2007). The teachers' role are as facilitators to provide input and activities for students to willingly engage in communication, explore themselves, and have freedom to use their own linguistic resources in leaarning the target language. The more learners actively participate in the task, the more they learn and improve their language skills.

As students do the communicative task, it is expected that they take part in negotiation meaning process and using the strategies like comprehension, confirmation, and clarification that can lead to a better language output. Teachers as the course designer have an important role to choose the appropriate task which attract learners' interest, suitable to their language skill, and promote their language performance (Phi Ho \& Hai Long, 2014). Willis \& Willis (2007) suggest that teachers should understand the three cycles of task procedures that can guide them to sequence their activities in TBLT class. Those task cycles generate interaction facilitated by a task that later can trigger language awareness and development of the learners. The task cycles are pre task, task cycle, and language focus. On the first cycle, teachers scaffold and provides the introduction to the topic. It includes the explanation about the related-words and the instruction of the task. The goal of this phase is to reduce the task complexity and familiarize learners to the topic by showing similar example e.g on video or dialogue or text.

The second cycle, allows learners to use their language knowledge to execute the task. They are allowed to do the task individually, in pair, or in a small group under teachers guidance. The goal of this phase is to boost learners' confidence since they have freedom to discuss and engage in communication without teacher huge involvement in the process. The report activity about what they have discussed shows learners' linguistic ability. When they report their result, it opens a chance to exchange ideas between teams and create better meaning on their intention. Meanwhile in the third cycle, allows learners to analyze, investigate, and practice their task using the better form of language. 


\section{Debate}

Different task demands different language resource. In designing communicative speaking task for foreign language teaching, it is necessary to know the different functions of speaking in every day communication and the distinct purposes for which learners need the communication skills. In this research, we use the purpose of talk as performance. It refers to a monologue talk in public which exchanges information to audience, such as debate (Richards, 2008). Debate is close to a discussion but it follows a recognizable format i.e motion and sequence, using an proper opening and closing, assess by judges, and it is closer to formal language than conversational language (Flynn, 2007). Debate can be used as follow up task-based learning as problem solving and comparing activity. It provides learners chance to negotiate meaning and yet gives motivation in using the target language because teacher can adjust the topic into the one which is challenging but still reachable to learners thinking skill.

Debate is about defending arguments, persuading, and pleasing audience with convincing language that the arguments surpass the oppositions' (FEDS UI, 1998). There are two opposing team which are usually called as "pro" and "contra" team. Before debating, learners are given time to prepare, discuss, and organize their arguments between their team. Thus, provides learners with a safe surrounding to practice, take risk, and encourage them to engage in communication. (Kidd, 2002) adds that debate is good activity to develop learners' critical thinking, increase presentation skill, and improve teamwork.

\section{RESEARCH METHOD}

This research investigates the use of communication strategies in an EFL classroom during the completion of task-based debate activity. In line with that aim, this research is a qualitative study since it focuses on the depth of the comprehension of the described data rather than computing it. Observing the factual phenomenon process in the authentic setting is the main source of data, the key instrument is the researcher, and the data is gathered in the form of words. The subject of this study are 10 EFL intermediate level students in Sidoarjo. For gaining the data, the researcher observes, takes note, and records learners' verbal and non-verbal behaviour based on Dornyei's taxonomy of communication strategies. Words, phrases, and sentences are the verbal data while mime, eye gazes, gesture etc are non-verbal data in this research.

During the observation, researcher use field note to write activities, situation, and information related to the data during the learning process. Researcher also record the debate process in order to make sure that the data appered are observed completely and enable researcher to repeatedly review for deeper analysis. After the data is collected, it will be analyzed by the procedures 
proposed by Miles et al which are reducing the data, displaying the data, and drawing conclusion.

\section{FINDINGS}

The results of data analysis based on the aims of the research are presented in the following table. It's the overall use of communication strategies according to Dornyei (1995) during the English debate activities.

Table 1. EFL Learners' Use of Communication Strategies

\begin{tabular}{llc}
\hline Type of CS & Sub-Categories & Total Use \\
\hline Avoidance Strategies & Topic avoidance & 1 \\
& Message abandonement & 3 \\
\hline Compensatory Strategies & Circumlocution & 12 \\
& Approximation & 0 \\
& All purpose item & 19 \\
& Word coinage & 2 \\
& Literal translation & 5 \\
& Foreignizing & 3 \\
& Code switching & 25 \\
& Repetition & 20 \\
& Non linguistic mean & 17 \\
& Appeal for help & 22 \\
\hline Stalling Strategies & Fillers & 44 \\
\hline
\end{tabular}

The communication strategies used during the debate for the motion "online shopping is the best way to shop" are mainly to overcome the gap in the argument or opinion exploration. For instance, self-performance problems such as negative feelings, feeling nervous, lack of vocabularies, lack of topic knowledge and the linguistic problem such as the complexity of the topic-related word, minimum vocabularies and grammar knowledge play important roles in affecting learners' strategies selection.

\section{Avoidance Strategies}

This strategies marked by "keeping silent" or not participate further in the debate process. Learners' who have low motivation and language proficiency tend to use this strategy because they can't find way out to compensate for their weakness in linguistic knowledge and decide to leave the message unfinished. As Paribakht (1985) states that more proficient learners' will use more appropriate strategies to stay in line durng the communication. They will use their references either in linguistic structure or topic related knowledge to express more of their intention. Meanwhile, the less proficient learners' tend to omit lexically difficult words, causing them to not speak when they expect problems such as unknown 
vocabularies or grammar structure. Here are the avoidance strategies found in the debate:

SS3: "If you buy in Online Shop, the price of the thing is so cheap and you can ermm so you can save your money. And of course with online shop I forgot what to say ... yeah ... online shop ... like that".

SS1: "That's why you should buy from the original online store to make sure the product... (Pausing for a while)... so you should buy from the original store"

As we can see in the first example, SS3 as the "pro" members tried to explain more on the benefit of online shopping but he seemed hesitant because he forget the vocabularies that he wanted to say. In order to overcome it, he avoided it by saying "like that" and leave the topic behind and simply finished his argumentation. Meanwhile in the second example SS1 as the "contra" team tried to abandon the message unfinished. She paused for seconds because she had difficulties in delivering the meaning for the next sentence. So she repeated her previous target message.

\section{Compensatory Strategies}

This strategies alternate learners' problems during communication with all resourses available. When learners are eager to solve the communication gap rather than decreasing their communicative goal, they can use similar semantic feature to subtitue the intended meaning. The other way is by making up new words by all means to express the desired idea. Asking peers or teacher as the resorted source during the debate, using all kinds of non verbal device such as nodding and clapping, describing the lexical word into the target language, translating literally the term to the target language, and switching to L1 during the debate are considered as alternative strategies to keep the message within the communicative goals. Here are the compensatory strategies found in the debate:

SS2 : "I have the same opinion to say that it's easy, but do you what is "menyadari" in English? Realize that it means the other people .... smart but bad people that good at computer .... ah hacker also easy to hack your online account?"

SS4 : "OLShop is bad because we we we can only see the picture. Then, I don't think the picture is the same like the real product or we can say thats thats that the baddest side".

SS5 : "The next good aspect is free ongkir. Yes, free ongkir (pronunced "r" like native)". 
SS8 : "My turn yeah? Ok, for me I disagree because there's no filter for seller from the what's the name? The owner of the Shopee or Lazada".

SS6 : "Well, thats the nice stuff of OLShop, but there are dangerous stuff like free delivery or stuff you know."

SS7: "You also don't need to pay directly at the moment or no no no (,hand symboling paying cash money) needed".

From the findings above we can see that all of the compensatory strategies apper at students utterances. SS2 did appeal for teacher help strategy by directly asking the word that he didn't know in English. He also applied circumlocution since he describe the intended word into longer sentence to illustrate "hacker". Meanwhile, SS4 used repetition and word coinage strategies in which he tried his best to utter his intention. SS5 applied two strategies in his utterance. He applied code switching and foreignizing. First, he is either forgot to translate "ongkir" which is "ongkos kirim" in bahasa Indonesia into English or he used to say it like that because it's an abbreviation word. Then, he seemed realize that "ongkir" is bahasa Indonesia. But he did not know the English, so he prononce it like an English word. Thus, able to overcome his bcommunication gap smoothly.

SS8 did literal translation strategy because he literally translate from his L1 which is bahasa Indonesia to the target language his deliberated L1 meaning is "giliran saya, ya?". When it says in English, it should be "Is it my turn?". SS6 tend to use all-purposed item strategy by frequently repeating the word "stuff" which has general meaning to carry out his intention. SS7 did non-linguistic strategy which he did gesture to demostrate what he wanted to say. He used it to enable audience understand the word "cash" through his action.

\section{Stalling Strategies}

This strategies are employed for time-gaining process. By using fillers or hesitation devices, learners are able to give time for themselves to think about the alternative solution to keep the communication channel flow. It also gives them opportunities to recall their memory of the target language-related knowledge. Here are the stalling strategies found in the debate:

SS8: "Hmm, well, I think that's a nice idea of the benefit. But doing OL shopping is 50:50 because it also sell negative thing."

SS4 : "In my opinion, $\boldsymbol{e} \boldsymbol{e} . . . \boldsymbol{e} \boldsymbol{e} . .$. OLShop is... bad because .. $\boldsymbol{e} \boldsymbol{e} . .$. there are so many sellers sell the $\boldsymbol{e} e . .$. fake things". 
This strategy used by learners mostly for giving them time to fill the pauses and think about their next utterances. SS8 used hedges whic is a vague language to calm his nervousness. He used it in the beginning of his speech to arrange his next utterance nicely. Meanwhile, SS4 simply applied fillers to prolong his thinking time during the debate.

\section{DISCUSSION}

This study is aimed at exploring the communication strategies used by EFL learners in task-based English debate. The application of TBLT procedures were clearly seen from the beginning of the lesson. Teacher gave the materials in a good sequence from the pre-task in which teacher played a video related to debate and asked students about how they usually shop nowadays. It gave a proper scaffolding process to students. In an instance, the class became lively and students felt motivated because they know that the topic for today's debate was something that challenged them. Topic that was close to their real-life experience. Yet, it still reachable to students knowledge to talk about. The task cycle phase promote students-centered learning because teacher allowed students to discuss and use any language source that enable them to find much more information. It also enhanced students in natural social interaction between them. They shared ideas, exchanged opinion, and solved their task by themselves. Hence, teacher as facilitator monitored their discussion and did not involve much because she wanted to give much opportunities for students to use the langugae as many as they can. Teacher attention was more to students who had difficulties to convey ther intention. Teacher gave them more priorities to be helped.

Related to the communication strategies used, it was found that strategies by Dornyei presented in the debate activity i.e topic avoidance, message abandonement, circumlocution, word coinage, all-purposed item, literal translation, foreignizing, repetition, non-linguistic mean, code witching, appeal for help, and stalling strategies. Appeal for help to teacher such as in "what is “menyadari” in English?" was dominantly used by learners' to overcome their problem in trust-worthy way. They believed that teacher will always "be there" to help them and teacher will provide the correct answer to their question. This strategies considered top three used by learner during the debate.

Next, code switching was also the most favourable strategies for the learners. Terms like "free ongkir" emerged because learners lack of vocabularies and indolecence to find another way out. Thus, in line with the finding in Pangaribuan et al. (2020) and Lucero \& Rosa (2017) researches which showed that code switching was dominantly used by the participants. The use of it was influnced by the inter-language skill and the cultural background of the participants. Thus, make students feel at ease and comfortable to switch to their L1 during the communication. Meanwhile, the top strategies used by learners is 
stalling strategies such as using "e..e.", "mmm", "errr", "uh" to overcome their communication problems. This device is used to prolong their time to think, keep the communication channel available, and maintain the discourse at the time when facing the difficulties.

\section{CONCLUSION}

Through observation, it can be concluded that most learners applied communication strategies in the debate activities. Most strategy used is stalling strategies such as fillers since is considered very easy and quick for learners to use when they encounter problems such as nervous, lack of vocab, and lack of grammar structure.

\section{REFERENCES}

Bialystok, E. (1990). Communication Strategies: A Psychological Analysis of Second Language Use. London: Basil Blackwell Ltd.

Brown, H. D. (2000). Teaching by Principles: An Interactive Approach to Language Pedagogy (Second Edition). New York: Pearson Longman.

Cunningham, F. M. (1999). English Language Learners' Speaking Skill. ERIC Digest, 8(1), 84-102.

Dornyei, Z. (1995). On the Teachability of Communication Strategies. Teachers of English to Speakers of Other Languages, Inc. (TESOL), 29(1), 55-85.

Faerch, C., \& Kasper, G. (1983). Strategies in Interlanguage Communication. New York: Longman Inc.

Flynn, C. (2007). Debating Tutorial Handouts. London: World Debating Society.

Formasi English Debating Society (FEDS). (1998). Debating Society Universitas Indonesia: Guidelines for Debaters. Depok: Universitas Indonesia Press.

Ghout-Khenoune, L. (2012). The Effects of Task Type on Learners' Use of Communication Strategies. Procedia - Social and Behavioral Sciences, 770-779.

Hasan, A., A., A. (2014). The Effect of Using Task-Based Learning in Teaching English on the Oral Performance of the Secondary School Students. International Interdisciplinary Journal of Education, 3(2), 250-264.

Hashemi, M., Azizinezhad, M., \& Darvishi, S. (2012). Using Task-based Language Teaching, Learning Practically in English Classes. Procedia Social and Behavioral Sciences, 526-529.

Kidd, A. (2002). The Oxford Union Rough Guide to Debating. London: Oxford University Press.

López, M. M., \& de Quintana, U. (2011). Speaking Strategies Used by BA ELT

Students in Public Universities in Mexico. MEXTESOL Journal, 35(1), 1-22.

Lucero, E., \& Rosa, M. (2017). Classroom Interaction in ELTE Undergraduate Programs. Characteristics and Pedagogical Implications, Colomb. Appl. Linguist. Journal, 19(2), 193-208. 
Pangaribuan, D., Agustina, S., Pratiwi, A., Manalu, E., \& Sembiring, Y. br. (2020). Communication Strategies Used by Teacher. Linguistic, English Education and Art (LEEA) Journal, 3(2), 274-286.

Paribakht, T. (1985). Strategic Competence and Language Proficiency. Applied Linguistics, 6(2), 132-146.

Phi Ho, P., \& Hai Long, N. (2014). The Impacts of Task-Based Speaking Activities on English-Majored Freshmen's Oral Performance at Ba RiaVung Tau Teacher Training College. Journal of Science Ho Chi Minh City Open University, 3(11), 19.

Popescu, A.-V., \& Cohen-Vida, M.-I. (2014). Communication Strategies for Developing the Learner's Autonomy. Procedia - Social and Behavioral Sciences, 3489-3493.

Putri, L. A. (2013). Communication Strategies in English as a Second Language (ESL) Context. Advances in Language and Literary Studies, 4(1), 129133.

Richards, J. C. (2008). Teaching Listening and Speaking from Theory to Practice. Cambridge: Cambridge University Press.

Rosas, M. (2018). L2 Learners Use of Communication Strategies as Affected by The Task Type. Revista Signos, 51(96), 107-131.

Tarone, E. (1980). Communication Strategies, Foreigner Talk, and Repair in Interlanguage. Language Learning, 30(2), 417-431.

Widia, L., \& Astawa, I. N. (2014). Improving Speaking Skill Through Task Based Learning Strategy at Seventh Grade Students of SMP Negeri 3 Baturiti in Academic Year 2012/2013. Jurnal Santiaji Pendidikan, 4(1), 1-13.

Willis, D., \& Willis, J. (2007). Doing Task Based Teaching: Oxford Handbook for Language Teaching. Oxford: Oxford University Press.

Xiao, R. (2009). Multidimensional Analysis and The Study of World Englishes. World Englishes, 28(4), 421-450. 